\title{
Breeding territory fidelity in a partial migrant, the American dipper Cinclus mexicanus
}

\author{
Holly A. Middleton, Christy A. Morrissey and David J. Green
}

\begin{abstract}
Middleton, H. A., Morrissey, C. A. and Green, D. J. 2006. Breeding territory fidelity in a partial migrant, the American dipper Cinclus mexicanus. - J. Avian Biol. 37: 369-
\end{abstract} 178.

\begin{abstract}
American dipper Cinclus mexicanus populations are frequently composed of resident individuals that occupy permanent territories year round and migratory individuals that overwinter with residents but migrate to breeding territories on higher elevation creeks each spring. Between 1999 and 2004 we examined how migratory strategy (resident/migratory) and sex differences influence breeding territory fidelity of American dippers occupying the Chilliwack River watershed, British Columbia, Canada. Counter to expectation we found that the migratory strategy of American dippers did not influence whether birds breeding in one year were found on their former breeding territory in the next. Migratory strategy also did not affect the probability that known surviving dippers occupied the same breeding territory in the following year. Males and females were equally likely to be found on their former territory in the following year (females $43 \%$, males $41 \%$ ) and known survivors had similar levels of breeding territory fidelity (females $74 \%$, males $68 \%$ ). However, breeding territory fidelity of males and females varied in response to different factors. Surviving female dippers were more likely to be found on their former breeding territory in the subsequent year following a successful breeding attempt than an unsuccessful breeding attempt. Prior reproductive performance did not influence whether surviving male dippers were found on their former breeding territory. Male dippers were more likely to be found on their former territory and, if they survived, have higher breeding territory fidelity when their mate also returned to that same territory. Mate retention also influenced whether females were found on their former territory in the following year but had no effect on the breeding territory fidelity of known survivors. We argue that sex-specific dispersal decision rules in American dippers are driven by sex differences in the predictability of breeding performance between years and sex differences in how mate retention influences subsequent reproductive success.
\end{abstract}

H. A. Middleton and D. J. Green (correspondence), Centre for Wildlife Ecology, Department of Biological Sciences, Simon Fraser University, 8888 University Drive, Burnaby, BC V5A 1S6 CANADA. E-mail: djgreen@sfu.ca. C. A. Morrissey, Canadian Wildlife Service, 5421 Robertson Road, Delta, BC V4K 3N2 Canada.

Strong breeding territory fidelity has been observed in many species of birds (Greenwood 1980, Greenwood and Harvey 1982). Individuals are thought to benefit from returning to a previously occupied breeding territory because familiarity with a territory can promote foraging efficiency or predator avoidance, reduce conflicts with neighbours and facilitate mate retention which in turn enhances reproductive success (Hinde 1956, Hoover 2003). Nevertheless, there is considerable varia- tion in the levels of fidelity to a breeding territory both within and among species (e.g. brown thrasher Toxostoma rufum 13-30\%; Haas 1998, bobolink Dolichonyx oryzivorus 45-51\%; Bollinger and Gavin 1989, prothonotary warbler Protonaria citrea 34-96\%; Hoover 2003).

Studies examining factors that influence variation in levels of fidelity to a breeding territory in bird species have frequently found that males are more site-faithful 
than females (Greenwood 1980, Rohwer and Anderson 1988, Clarke et al. 1997, but see Reed and Oring 1993). Studies have also demonstrated that both males and females may be more likely to return to higher quality breeding territories (e.g. Lanyon and Thompson 1986, Bollinger and Gavin 1989, Newton 2001), or are more likely to be site faithful following a successful than unsuccessful breeding attempt (Pärt and Gustafsson 1989, Haas 1998, Hoover 2003). However, other studies have found that prior reproductive success only influences the territory fidelity of one sex, usually females (Drilling and Thompson 1988, Haas 1998), or has no effect on the return of either males or females (Bedard and Lapointe 1984, Bollinger and Gavin 1989, Howlett and Stutchbury 2003). Switzer (1993) used a dynamic model to show that prior reproductive success is more likely to influence dispersal decisions and territory fidelity when breeding performance is predictable but there is limited empirical data available to test this model (but see Beletsky and Orians 1987, and Bédard and Lapointe 1984 in Switzer 1993).

One factor likely to explain some of the variation in breeding territory fidelity among birds is whether they are resident or migratory (Murphy 1996). Studies have demonstrated that resident species frequently exhibit high levels of breeding territory fidelity (e.g. great tit Parus major 80\%, Harvey et al. 1979; superb fairy-wren Malurus cyaneus 90\%, Mulder 1995). Resident individuals may rarely disperse from breeding territories because of benefits associated with remaining on a familiar territory or costs associated with finding a superior territory or mate in a saturated habitat (Green et al. 2004). In contrast, migratory species appear to have more variation in breeding territory fidelity (e.g. brown thrasher Toxostoma rufum 22\%, Haas 1998; barn swallows Hirundo rustica 40\%, Shields 1984; eastern kingbirds Tyrannus tyrannus 83\%, Murphy 1996). To date no study has assessed the extent to which migration influences breeding territory fidelity using either the comparative method or by comparing the breeding territory fidelity of resident and migratory individuals from the same population (i.e. in partial migrants). In this paper we take the latter approach and examine how migratory strategies influence breeding territory fidelity in the partial migrant, the American dipper Cinclus mexicanus. American dipper populations include resident individuals that occupy restricted multipurpose territories year round and migratory individuals that overwinter with residents but make discrete seasonal movements between wintering areas and breeding territories on higher elevation creeks (Morrissey et al. 2004).

Previous work has demonstrated that resident dippers tend to have higher reproductive success than migrants as they initiate breeding earlier and are more likely to raise a second brood (Morrissey 2004). Migratory behaviour may therefore influence breeding territory fidelity of dippers both directly if migration limits the ability of individuals to reoccupy the previous year's breeding territory and indirectly if breeding dispersal decisions of individual dippers are sensitive to reproductive success. In this study we test the prediction that migratory dippers have lower breeding territory fidelity than resident dippers because the seasonal movements they undertake may delay their return, allowing new breeders to establish territory occupancy or because the lower reproductive success of migrants make them more likely to switch territories. In addition we evaluate whether breeding dispersal decisions of male and female dippers are sensitive to prior reproductive success or the territory fidelity of their mate.

\section{Methods}

\section{Study area and nest monitoring}

We studied American dippers in the Chilliwack River watershed in southwestern British Columbia $\left(49^{\circ} 02^{\prime} \mathrm{N}\right.$ and $\left.121^{\circ} 04^{\prime} \mathrm{W}\right)$. The watershed ranges from 50 to $2,500 \mathrm{~m}$ in elevation and drains an area of $1,200 \mathrm{~km}^{2}$. Breeding birds were monitored at eight sites along $43.5 \mathrm{~km}$ of the main stem of the Chilliwack River and on seven tributaries. The eight sites on the river were each approximately $2 \mathrm{~km}$ long and separated by intervals of approximately $4-5 \mathrm{~km}$, while accessible sections of each tributary ranged from 1 to $3 \mathrm{~km}$ in length. Additional details of the study area are provided in Morrissey et al. (2004). There are two classes of American dippers in this watershed; residents that occupy multipurpose river territories year round and migrants that overwinter with residents but make regular seasonal movements to separate breeding territories on creeks at higher elevations (Morrissey et al. 2004). Radiotelemetry data found that the majority (8/10) of tagged migratory individuals made short distance altitudinal movements of 2 to $17 \mathrm{~km}$ (mean $=7.5 \mathrm{~km}$ ) between their wintering and breeding areas. The remaining two migrants were not relocated and may have moved greater distances to breeding areas outside the watershed (Morrissey et al. 2004). In this paper, we distinguish between resident birds that bred on the river and were never observed more than $2 \mathrm{~km}$ from their territory year round and altitudinal migrants that either winter on the river or outside the watershed and occupy breeding territories on creeks at least $5 \mathrm{~km}$ upstream from the main stem of the river between March and July.

Over the course of the study we located sixty-two distinct breeding territories. On average, we monitored 21 territories per year $(74 \%)$ occupied by resident pairs and 7 territories per year $(26 \%)$ occupied by migratory pairs. Territories were defined as the area containing a nesting site and adjacent foraging areas defended by a breeding pair against other dippers during the breeding 
season. We captured adult birds in mist-nets set up across streams at wintering and breeding sites. Birds were marked using unique combinations of three colour bands and a metal USFWS band. No band loss was ever observed. The sex of breeding individuals was determined by the presence of a brood patch or by using behavioural cues as only female American Dippers incubate eggs and brood young (Kingery 1996). Our analysis of breeding territory fidelity draws on data from a total of 139 pair-years (105 residents, 34 migrants) and 134 colour-banded individuals ( 71 female, 63 male).

\section{Reproductive success}

Breeding birds were monitored from the nest-building period (early March) until completion of the final nesting attempt (late July) in each year. Nests were visited every 2-3 days to determine hatching date, clutch size, brood size and fledging date. The success of a breeding attempt was determined by visiting the nest for several days surrounding the predicted fledging day. Breeding attempts were considered successful if one or more fledged young was observed. Productivity of breeding attempts was determined by the number of nestlings that survived to banding age (typically 12 days old, range 10-14 days) as it was not always possible to accurately determine the numbers of fledged young. The most prevalent causes of breeding failure over the five years of this study were predation (40.7\%) and flooding (23.7\%). Female dippers initiated second clutches following both successful and failed breeding attempts (on average, $43 \%$ of females initiated $>1$ clutch). However, males and females rarely switched territories or mates mid-season (1 of 172 male-years, 0 of 172 female-years).

\section{Assessing fidelity to a breeding territory}

Fidelity to a breeding territory has previously been calculated as either the proportion of all individuals breeding in one year that are found to occupy the same breeding territory in the next (e.g. Harvey et al. 1979), or as the proportion of surviving individuals that reoccupy their former breeding territory (e.g. Hoover 2003, Howlett and Stutchbury 2003). We therefore classified the behaviour of resident and migratory dippers into the following categories. Resident birds in year 1 either (1) survived and occupied the same territory in the following year, (2) survived but moved to a different territory in the following year, or (3) were never seen in subsequent years so had either died or survived but moved to an unknown location. Migrants that bred on higher elevation creeks in year 1 all left their breeding territories and moved to separate wintering areas. Migrants subsequently either (1) survived and moved back to occupy the same breeding territory the following year, (2) survived but moved to a different breeding territory in the following year, or (3) were never seen in subsequent years so had either died or survived but moved to an unknown location. We then examined what influenced both the breeding territory fidelity of all birds (an analysis that would include birds that had not survived from one breeding season to the next), and the breeding territory fidelity of known survivors (an analysis that may have excluded some individuals that had moved but not been relocated).

Marked individuals were relocated during systematic censuses of the watershed conducted five times per year, non-systematic searches during the breeding season and weekly visits made to breeding territories between April and July each year. Breeding territories and nest sites located in one year were revisited in all subsequent years of the study to determine whether individuals reoccupied former territories. Non-systematic searches extended approximately $1 \mathrm{~km}$ beyond the boundary of the outermost territory in each linear section of river or creek that was monitored. Individuals that left their former territory could therefore be relocated if they dispersed a short distance $(0-3 \mathrm{~km})$ to a new breeding territory within a monitored section of river or creek, moved a distance of 5-15 km between creek territories and the closest breeding territories on the river, or made longer movements of 4-32 km between the eight linear study plots on the river.

\section{Predictability of breeding performance}

Year to year predictability of breeding performance was determined by comparing the reproductive success of male and female dippers that occupied the same territory in their first and second breeding season as marked birds. This allowed us to evaluate the potential benefit that could be obtained by basing breeding dispersal decisions on the previous year's reproductive success (sensu Hoover 2003). To determine whether predictability of breeding performance was associated with attributes of the territory rather than the breeding pair we also evaluated whether success or failure on a territory in the first year predicted breeding performance in a subsequent year of the study.

\section{Statistical analysis}

We examined whether the breeding territory fidelity of male and female American dippers was influenced by migratory strategy (resident/migrant), prior reproductive success, and mate retention (return of a mate from the previous breeding season: yes/no). Prior reproductive performance of a pair was initially categorized as a binary variable (success or failure to fledge one or more young in a breeding season). However, we also examined 
how breeding territory fidelity was influenced by past productivity, estimated as the sum of the number of young raised to banding age during all breeding attempts over the course of a breeding season. We treated each year's data as independent since the majority of pairs were represented only once (105 of 139 pairs) and only 5 pairs were represented in more than 2 years. Analyses were conducted using both univariate logistic regression and multivariate stepwise logistic regression since the former allowed us to include all marked individuals including those whose mate was unmarked. In stepwise regression analysis we started with a full model that included all main effects and twoway interaction terms, and sequentially eliminated all non-significant $(\mathrm{P}>0.05)$ interaction terms followed by all non-significant main effects to obtain a final model. No interaction terms were significant in any analyses (all $\mathrm{P}>0.1$ ). Statistical analyses were performed using SPSS version 11.0.

\section{Results}

\section{Territory reoccupancy between years}

Approximately $40 \%$ of American dippers occupying a breeding territory in the Chilliwack River watershed in one year occupied the same breeding territory in the next (males: $41 \% \mathrm{n}=121$ bird-years; females: $43 \% \mathrm{n}=122$ bird-years). The likelihood that male and female dippers breeding in one year would be found on their former breeding territory in the next was not influenced by their migratory strategy, either considered alone or after controlling for reproductive success, mate retention and year (Table 1). Female dippers, however, were more likely to be found on their former breeding territory if they had fledged at least one young in the previous year than if they had failed to fledge any young (Table 1). In contrast, reproductive success did not significantly effect whether male dippers would be found on their former breeding territory in the following year (Table 1). Both males and females were more likely to be found on their former breeding territory if their mate also returned to the same territory in the following year (Table 1). The likelihood that male and female dippers breeding in one year were found to occupy the same territory in the following year also varied between years, with the territory fidelity for males being relatively high in 2000 and 2003, and the territory fidelity of females was highest in 2000 and lowest in 2004 (Table 1).

\section{Breeding territory fidelity of surviving dippers}

Approximately $60 \%$ of American dippers breeding in the Chilliwack River watershed were known to survive from one breeding season to the next (males: mean $=62 \%$. range $=52-70 \%$; females: mean $=58 \%$, range $=37-$ $74 \%, \mathrm{n}=5$ years). Known survivors demonstrated a high degree of breeding territory fidelity (males: 68\%, $n=75$ bird-years; females: $74 \%, n=72$ bird-years). Male and female breeding territory fidelity was not affected by individual migratory strategy, either when considered alone or after controlling for mate retention, year and previous reproductive success (Fig. 1, Table 2). Female dippers that had fledged at least one young were more likely to be faithful to their breeding territory than females that had fledged no young the previous year (Fig. 2). Further examination of the relationship between female breeding territory fidelity and productivity in the previous year suggested that female territory fidelity first increased in response to increasing numbers of young fledged per season and then reached an asymptote (Fig. 3, change in deviance $=16.3, \mathrm{df}=1$, $\mathrm{P}<0.001)$. In contrast, the breeding territory fidelity of male dippers did not vary significantly with the previous year's reproductive success (Fig. 2, Table 2). Male dippers, however, had higher breeding territory fidelity if their mate returned to the previous year's territory than if their mate failed to return (Fig. 4, Table 2). Breeding territory fidelity also varied slightly by year (male: range $53-83 \%$; female: range $60-85 \%$ ), but the interannual variation was not statistically significant for either males or females.

\section{Pair breeding experience and reproductive success}

Males that reoccupied their former breeding territory had higher reproductive success if they were paired with the same female than paired with a new female (Fig. 5; $\left.t_{26}=2.40, P=0.02\right)$. However, for females that reoccupied their former breeding territory, reproductive success was high regardless of whether they were paired with the same or a new male (Fig. $5 ; \mathrm{t}_{28}=0.04, \mathrm{P}=0.97$ ).

\section{Predictability of breeding performance}

When an individual occupied a territory in two consecutive years the probability that the reproductive outcome (success or failure to fledge at least one young) was consistent between years was significantly higher for female than male dippers (Fig. $6 ; \chi^{2}=6.38, \mathrm{P}=0.01$ ). The predictability of an individuals breeding performance was not confounded by the use of the same territory in each year. The reproductive outcome on a territory in the first year it was monitored did not predict the reproductive outcome in a randomly selected future year $(53 \%$ of territories had a consistent reproductive outcome, $\mathrm{n}=38$, binomial test, $\mathrm{P}>0.25$ ). 
Table 1. Summary of logistic regression analyses examining factors that influence the likelihood male and female American dippers breeding in one year are relocated on their former breeding territory in the next.

\begin{tabular}{|c|c|c|c|c|c|}
\hline & \multirow[b]{2}{*}{ Proportion relocated (n) } & \multicolumn{2}{|c|}{ Univariate analyses } & \multicolumn{2}{|c|}{ Multivariate analyses } \\
\hline & & $\Delta \mathrm{Dev}$ & $\mathrm{P}$ & $\Delta \mathrm{Dev}$ & $\mathrm{P}$ \\
\hline \multicolumn{6}{|c|}{ Males: } \\
\hline \multicolumn{6}{|c|}{ Migratory strategy } \\
\hline migrant & $0.37(27)$ & & & & \\
\hline resident & $0.43(94)$ & 0.27 & 0.68 & 1.92 & 0.17 \\
\hline \multicolumn{6}{|l|}{$\mathrm{RS}$} \\
\hline fail & $0.30(33)$ & & & & \\
\hline succeed & $0.47(85)$ & 2.80 & 0.09 & 0.70 & 0.40 \\
\hline \multicolumn{6}{|c|}{ Mate returns } \\
\hline no & $0.28(60)$ & & & & \\
\hline \multirow{2}{*}{\multicolumn{6}{|c|}{ Year }} \\
\hline & & & & & \\
\hline 2000 & $0.50(20)$ & & & & \\
\hline 2001 & $0.37(35)$ & & & & \\
\hline 2002 & $0.37(30)$ & & & & \\
\hline 2003 & $0.53(17)$ & & & & \\
\hline 2004 & $0.37(19)$ & 2.23 & 0.69 & 4.19 & 0.38 \\
\hline \multicolumn{6}{|c|}{ Females: } \\
\hline \multicolumn{6}{|c|}{ Migratory strategy } \\
\hline migrant & $0.31(29)$ & & & & \\
\hline resident & $0.47(93)$ & 2.44 & 0.12 & 1.47 & 0.23 \\
\hline \multicolumn{6}{|l|}{$\mathrm{RS}$} \\
\hline fail & $0.29(35)$ & & & & \\
\hline succeed & $0.51(84)$ & 5.27 & 0.02 & 5.39 & 0.02 \\
\hline \multicolumn{6}{|c|}{ Mate returns } \\
\hline no & $0.31(63)$ & & & & \\
\hline yes & $0.57(43)$ & 7.29 & 0.007 & 6.90 & 0.01 \\
\hline \multicolumn{6}{|l|}{ Year } \\
\hline 2000 & $0.71(17)$ & & & & \\
\hline 2001 & $0.49(35)$ & & & & \\
\hline 2002 & $0.44(34)$ & & & & \\
\hline 2003 & $0.43(14)$ & & & & \\
\hline 2004 & $0.14(22)$ & 14.63 & 0.006 & 10.53 & 0.02 \\
\hline
\end{tabular}

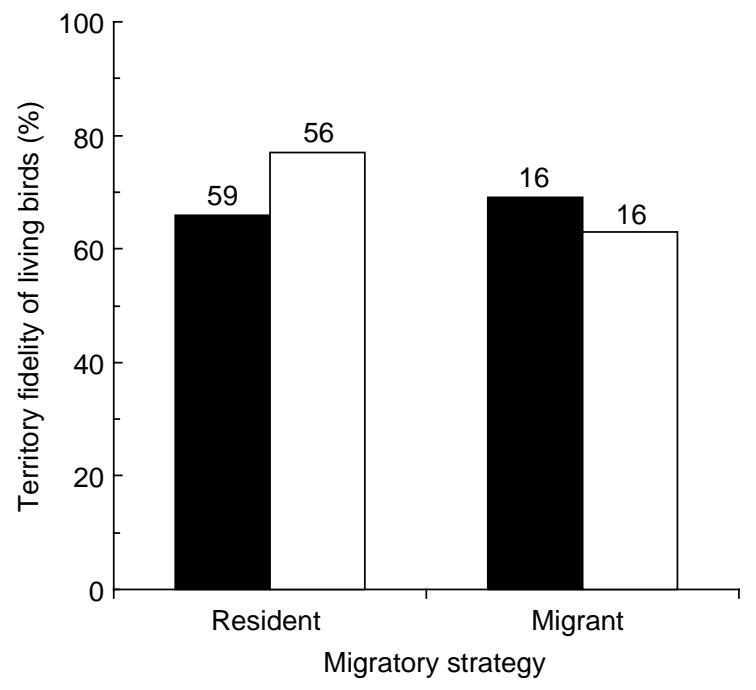

Fig. 1. Breeding territory fidelity of male (filled bars) and female (open bars) American dippers in relation to their migratory strategy (resident or migratory). Numbers above bars represent numbers of individual birds in each category.

\section{Discussion}

We found that over $40 \%$ of American dippers breeding in the Chilliwack River watershed in one year were relocated on the same territory in the following year and approximately $70 \%$ of known survivors were faithful to the previous year's breeding territory. Price and Bock (1983) similarly found high levels of breeding territory fidelity in a Colorado population of dippers. In contrast to our predictions, we found little evidence to suggest that migratory behaviour had an effect on breeding territory fidelity of dippers in the Chilliwack River population. Intriguingly, however, we found that male and female dippers appeared to use different dispersal decision rules. Breeding territory fidelity of female dippers was influenced by prior reproductive success whereas breeding territory fidelity of males was more sensitive to whether they retained their mate from the previous year.

\section{Migratory strategy and breeding territory fidelity}

Migratory behaviour was predicted to affect breeding territory fidelity in two ways. First, migrants would be expected to have lower territory fidelity than resident 
Table 2. Summary of logistic regression analyses examining factors that influence the breeding territory fidelity of male and female American dippers known to survive from one year to the next.

\begin{tabular}{|c|c|c|c|c|}
\hline & \multicolumn{2}{|c|}{ Univariate analyses } & \multicolumn{2}{|c|}{ Multivariate analyses } \\
\hline & $\Delta$ Dev & $\mathrm{P}$ & $\Delta$ Dev & $\mathrm{P}$ \\
\hline \multicolumn{5}{|l|}{ Males } \\
\hline Migratory strategy (resident/migrant) & 0.01 & 0.94 & 0.48 & 0.49 \\
\hline Reproductive success (fail/succeed) & 0.66 & 0.41 & 0.02 & 0.89 \\
\hline Mate returns (yes/no) & 4.40 & 0.04 & 4.40 & 0.04 \\
\hline Year & 2.48 & 0.65 & 5.20 & 0.27 \\
\hline \multicolumn{5}{|l|}{ Females } \\
\hline Migratory strategy (resident/migrant) & 1.24 & 0.27 & 0.25 & 0.62 \\
\hline Reproductive success (fail/succeed) & 9.71 & 0.002 & 9.71 & 0.002 \\
\hline Mate returns (yes/no) & 2.81 & 0.09 & 1.84 & 0.18 \\
\hline Year & 3.70 & 0.45 & 2.49 & 0.65 \\
\hline
\end{tabular}

dippers if migration reduced the ability of individuals to retain their breeding territory under competition from conspecifics. Second, migrants with lower reproductive success than residents would be expected to be more likely to switch territories if they can improve their reproductive success by moving to a breeding territory on the overwintering grounds. However, we found that the migratory behaviour of American dippers had no effect on breeding territory fidelity either when considered alone or after controlling for differences in reproductive success. Breeding territory fidelity was high for dippers regardless of migratory strategy. We present three possible explanations for the lack of difference in breeding territory fidelity between resident and migratory dippers.

One reason breeding territory fidelity may not differ between migrants and residents is that the costs of switching territories may outweigh any benefits migrants

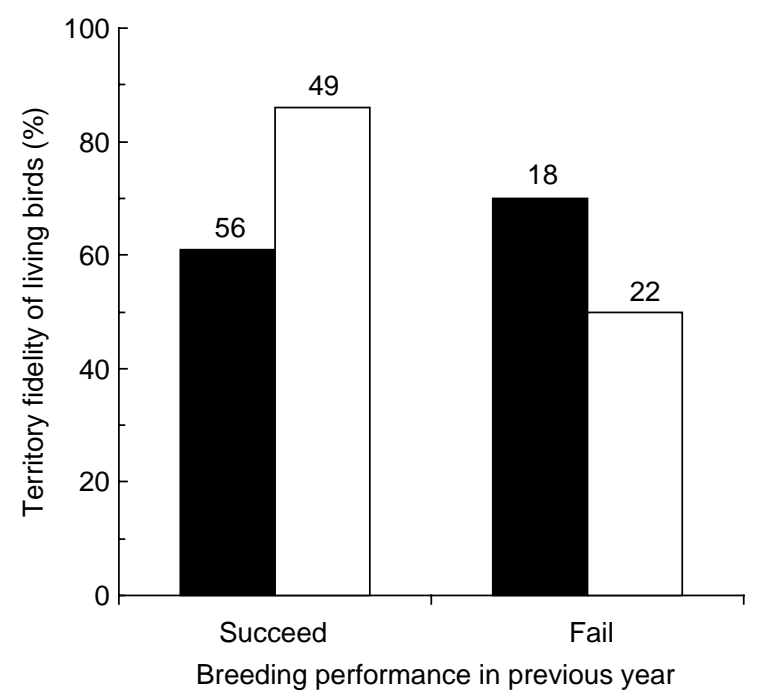

Fig. 2. Breeding territory fidelity of male (filled bars) and female (open bars) American dippers in relation to their breeding performance (succeed or fail to fledge at least one offspring) in the previous year. Numbers above bars represent numbers of individual birds in each category. could obtain by breeding where they overwinter. Breeding dispersal does lead to reduced survival or reduced productivity in the subsequent breeding season. For example, Désrochers and Magrath (1993) found that breeding dispersal reduced the subsequent reproductive success of blackbirds Turdus merula by 0.93 young. We are not able to directly measure the costs associated with switching from being migratory to being resident. However, we can estimate the reproductive cost at which migrants will obtain no net benefit from becoming a resident (breeding where they overwinter; Appendix 1). Our analysis suggests that even if switching reduces reproductive success in the following year by more than $50 \%$ (approximately 2 offspring) migrants would still benefit from becoming resident. The large productivity cost that can be tolerated suggests that this hypothesis is unlikely to explain why migrants do not have lower territory fidelity than residents.

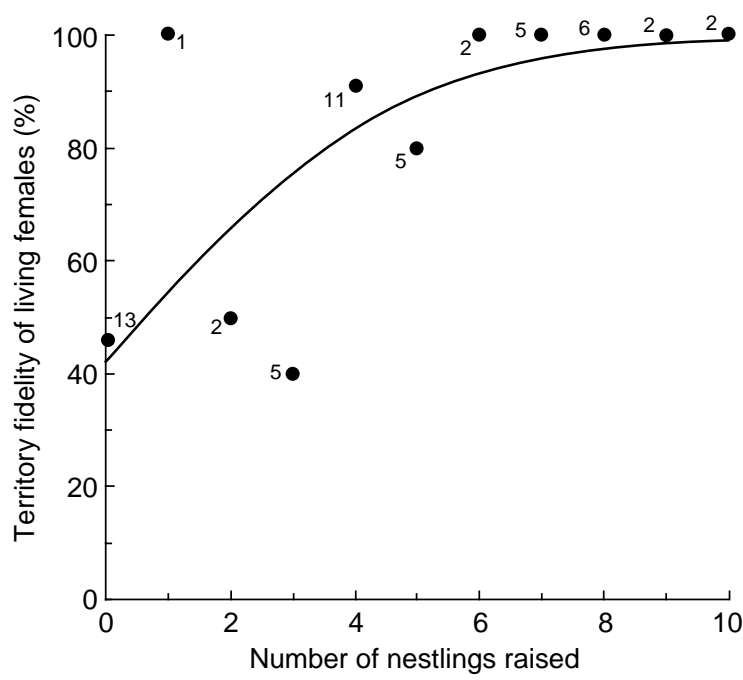

Fig. 3. Relationship between female breeding territory fidelity and the total number of nestlings raised to banding age (10-14 days) in the previous breeding year. Numbers indicate sample size for each point. 


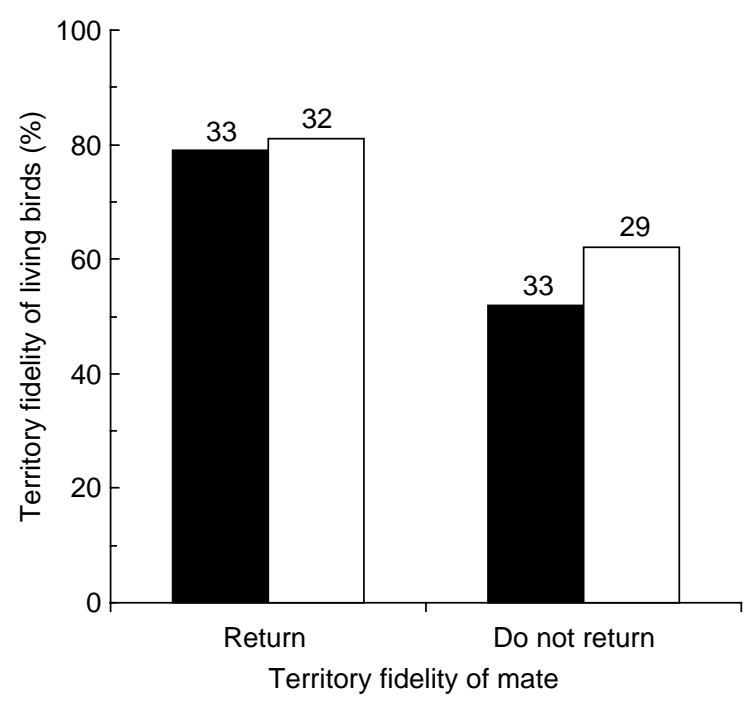

Fig. 4. Breeding territory fidelity of male (filled bars) and female (open bars) American dippers in relation to the territory fidelity of their mate. Numbers above bars represent numbers of individual birds in each category.

An alternative explanation for why breeding territory fidelity is similar among resident and migratory dippers is that migratory strategies are fixed behaviours associated with distinct morphological and physiological characteristics. Migration strategies in other species of partial migrants are argued to be genetically determined. Biebach (1983), for example, showed that offspring of European robins Erithacus rubecula were more likely to adopt the strategy of their parents than the alternate strategy. Furthermore, adult European robins have never

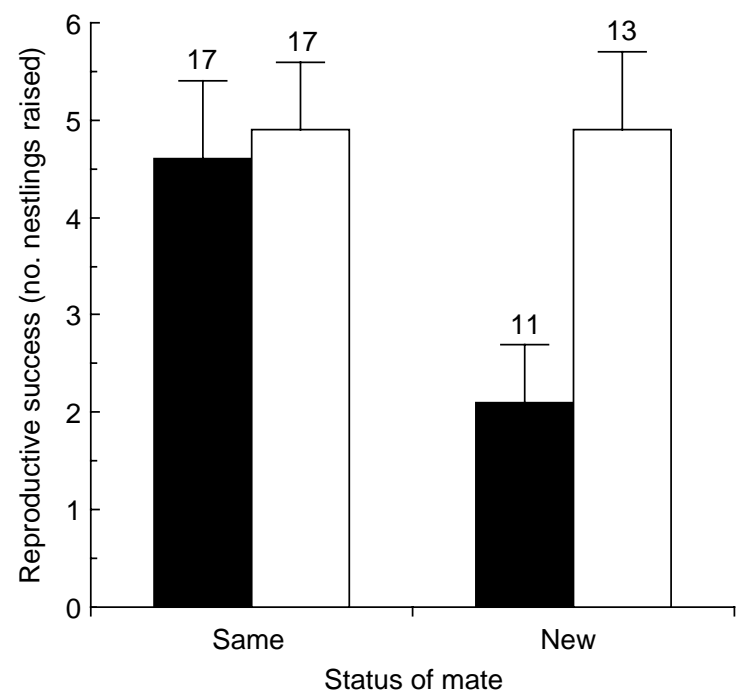

Fig. 5. Reproductive success $( \pm \mathrm{SE}$ ) of male (filled bars) and female (open bars) American dippers that breed with the same or a different mate upon returning to their previous breeding territory. Numbers above bars represent numbers of individual birds in each category.

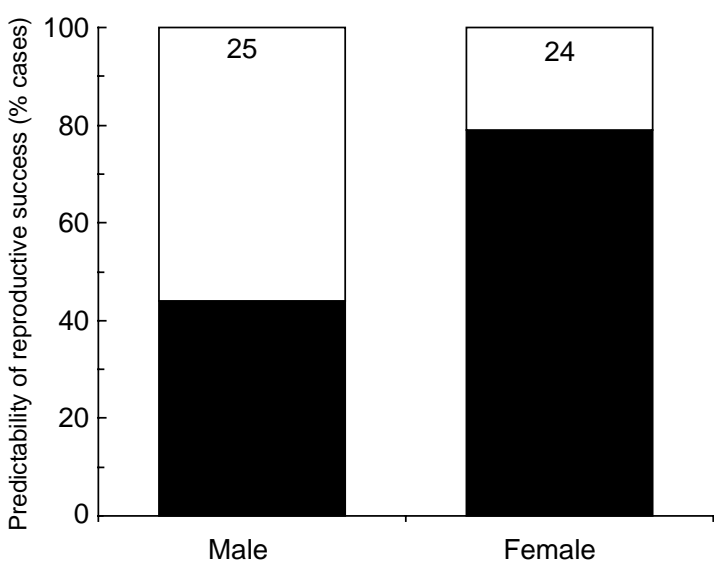

Fig. 6. Predictability of breeding performance for male and female American dippers that bred on the same territory from one year to the next. Filled areas show percentage of individuals whose breeding performance (success or failure to raise at least one fledgling) was the same in both years. Numbers within bars represent numbers of individual birds in each category.

been observed to switch from being migratory to being resident (Adriaensen and Dhondt, 1990). We have limited data on the relation between parental and offspring migratory strategies in dippers. However, $35 \%$ $(n=17)$ of recruited offspring behaved differently from their parents suggesting that migratory strategies are not completely based on parental genotypes. Nevertheless only 1 of 139 marked dippers has ever been observed to switch strategies during the course of this study. We are currently investigating whether migrants have distinct morphological or physiological traits that limit their ability to compete for the higher quality territories at lower elevations.

Finally, the lack of a relationship between migratory strategy and breeding territory fidelity may result because the short distance traveled by migratory individuals in this study does not significantly constrain breeding territory fidelity. This explanation is plausible as wintering and breeding areas in this study are only separated by a few kilometers (range $=5-60 \mathrm{~km}$ ). Nevertheless, it is likely that some migrant breeders in this study overwinter outside the Chilliwack River watershed and travel greater distances between wintering and breeding grounds. Only $46 \%$ of breeding migrants $(\mathrm{n}=37)$ are relocated on winter censuses of the Chilliwack River and 2 of 10 radiotagged overwintering migrants were not relocated on breeding territories within the Chilliwack River watershed (Morrissey et al. 2004). Price and Bock (1983) have also argued that some migratory American dippers breeding in Colorado make between-watershed migratory movements. If migration constrained breeding territory fidelity we would therefore have expected to detect its effect in our dataset. More detailed data on the distances traveled by migratory dippers are required to determine whether long- 
distance migratory movements have a greater effect on the breeding territory fidelity of American dippers.

\section{Reproductive success and breeding territory fidelity}

Previous reproductive success has frequently been shown to influence the breeding dispersal decisions of many birds (Gavin and Bollinger 1988, Bollinger and Gavin 1989, Haas 1998, Hoover 2003). We demonstrated that female breeding territory fidelity was sensitive to prior reproductive success. Males, however, were not clearly affected by their prior reproductive success. Other studies have also documented sex-differences in the relationship between prior reproductive success and breeding territory fidelity (e.g. Drilling and Thompson 1988, Murphy 1996). Switzer (1993) and Hoover (2003) argued that individuals should only base dispersal decisions on prior reproductive success when reproductive outcomes are predictable between years. Our data are consistent with this argument since the reproductive success of female, but not male, dippers could be predicted by their previous reproductive success at a territory. Female dippers therefore appear to base dispersal decisions on a reliable cue to future reproductive success and are likely to benefit from reoccupying or avoiding territories where they were previously successful or unsuccessful. Sex-differences in the predictability of reproductive outcomes may therefore provide an adaptive explanation for sex-differences in the breeding dispersal decision rules of many other birds.

\section{Mate retention and breeding territory fidelity}

We found that American dippers were far more likely to be relocated on a former breeding territory if they retained their partner from the previous year. This pattern could arise because the shared reproductive history of a pair influences the mortality of both partners or because breeding dispersal decisions of both males and female dippers are influenced by mate retention. Mate retention in other species has been found to confer a reproductive advantage by allowing pairs to initiate breeding earlier thus increasing nestling quality (Murphy 1996, Monros et al. 2002) or allowing pairs to initiate more breeding attempts (Rowley 1983, Désrochers and Magrath 1993). The extent to which mate retention influences breeding dispersal decisions can perhaps best be evaluated by examination of factors influencing the breeding territory fidelity of surviving individuals since such analyses are not confounded by mortality. In our study, mate retention influenced the breeding territory fidelity of surviving male but not female dippers suggesting that only the dispersal decision of male dippers is influenced by mate retention. In contrast, Aebischer et al. (1995) found that female shags
Phalacrocorax aristotelis were far more likely to be faithful to their breeding territory if their mate returned than if their mate was absent ( $83 \%$ vs. $6 \%$ ). Why should one sex base breeding dispersal decisions on mate retention while the other does not? Sex-differences in the use of mate retention as breeding dispersal decision rules may be expected if one sex obtains greater reproductive benefits from mate retention than the other. Our data are consistent with this explanation. Male dippers that retain their mate produce twice as many young as males that breed with a new female but female dippers that retain their mate have the same productivity as females that breed with a new male. Male dippers, like females, therefore appear to base dispersal decisions on a cue that influences their future reproductive success. Therefore, we suggest that for migratory males that usually arrive on breeding territories before females, the decision to disperse is likely to take place after they return to their former breeding territory but are not rejoined by their former mate.

In summary, our study shows that migration does not influence the breeding territory fidelity of American dippers even though migrants might be expected to obtain reproductive benefits from switching strategies and breeding in areas where they also overwinter. Importantly, however, we found that both migratory and resident dippers appear to use sex-specific dispersal decision rules that are likely to have a positive effect on their future reproductive success.

Acknowledgements - We would like to thank I. Pollett, R. McKibbin, D. Lissimore, M. Bandura and numerous volunteers for their tireless work in the field. We are also grateful to the Department of Fisheries and Oceans for accommodation and logistical support. R. Butler, R. Ydenberg and E. Krebs and four anonymous reviewers made insightful comments on earlier drafts of the paper. Funding to support this research was provided by an Environment Canada Science Horizons Youth Internship Grant to HAM, Environment Canada GBEI grant to CAM and an NSERC Discovery Grant to DJG.

\section{References}

Aebischer, N. J., Potts, G. R. and Coulson, J. C. 1995. Site and mate fidelity of shags Phalacrocorax aristotelis at two British colonies. - Ibis 137: 19-28.

Adriaensen, F. and Dhondt, A. A. 1990. Population dynamics and partial migration of the European robin (Erithacus rubecula) in different habitats. - J. Anim. Ecol. 59: 10771090.

Bedard, J. and Lapointe, G. 1984. The Savannah sparrow territorial system - can habitat features be related to breeding success? - Wilson Bull. 62: 1819-1828.

Beletsky, L. D. and Orians, G. H. 1987. Territoriality among male red-winged blackbirds: site fidelity and movement patterns. - Behav. Ecol. Sociobiol. 20: 21-34.

Biebach, H. 1983. Genetic determination of partial migration in the European robin. - Auk 100: 601-606.

Bollinger, E. K. and Gavin, T. A. 1989. The effects of site quality on breeding-site fidelity in bobolinks. - Auk 106: $584-594$. 
Clarke, A. L., Saether, B. E. and Roskaft, E. 1997. Sex biases in avian dispersal: a reappraisal. - Oikos 79: 429-438.

Désrochers, A. and Magrath, R. D. 1993. Environmental predictability and remating in European blackbirds. - Behav. Ecol. 4: 271-275.

Drilling, N. E. and Thompson, C. F. 1988. Natal and breeding dispersal in house wrens Troglodytes aedon. - Auk 105: $480-491$.

Gavin, T. A. and Bollinger, E. K. 1988. Reproductive correlates of breeding-site fidelity in bobolinks (Dolichonyx oryzivorus). - Ecology 69: 96-103.

Green, D. J., Krebs, E. A. and Cockburn, A. 2004. Mate choice in the brown thornbill (Acanthiza pusilla): are settlement decision, divorce and extrapair mating complementary strategies? - Behav. Ecol. Sociobiol. 55: 278-285.

Greenwood, P. J. 1980. Mating systems, philopatry and dispersal in birds and mammals. - Anim. Behav. 28: $1140-1162$.

Greenwood, P. J. and Harvey, P. H. 1982. The natal and breeding dispersal of birds. - Ann. Rev. Ecol. Syst. 13: 121.

Haas, C. A. 1998. Effects of prior nesting success on site fidelity and breeding dispersal: an experimental approach. - Auk 115: 929-936.

Harvey, P. H., Greenwood, P. J. and Perrins, C. M. 1979. Breeding area fidelity of great tits (Parus major). - J. Anim. Ecol. 48: 305-313.

Hinde, R. A. 1956. Biological significance of territories of birds. - Ibis 98: 340-369.

Hoover, J. P. 2003. Decision rules for site fidelity in a migratory bird, the prothonotary warbler. - Ecol. 84: 416-430.

Howlett, J. S. and Stutchbury, B. J. M. 2003. Determinants of between-season site, territory and mate fidelity in hooded warblers (Wilsonia citrina). - Auk 120: 457-465.

Kingery, H. E. 1996. American dipper (Cinclus mexicanus). - In: Poole, A. and Gill, F. (eds). The birds of North America, No. 229. The Academy of Natural Sciences, Philadelphia, PA. and The American Ornithologists' Union, Washington, D. C. 28 pp.

Lanyon, S. M. and Thompson, C. F. 1986. Site fidelity and habitat quality as determinants of settlement pattern in male painted buntings. - Condor 88: 206-210.

\section{Appendix 1}

\section{Calculating when switching from a migratory to resident strategy will not be beneficial}

We estimated the reproductive cost at which migrants would not benefit from switching to the more successful resident strategy by calculating the cost at which the residual reproductive value of individuals that switch strategies equals the residual reproductive value of individuals that remain migratory throughout their lifetime.

We estimated the residual reproductive value of individuals that were migrants in their first breeding season migrants, survived to the following breeding season and remained migratory throughout their life using Eqn 1:

$\operatorname{RRV}($ stay $)=\mathrm{RS}_{\text {year } 2}(\mathrm{~m})+\sum_{\text {year } 3}^{7} \mathrm{~S}_{\text {year }} \cdot \operatorname{RS}(\mathrm{m})$
Monros, J. S., Belda, E. J. and Barba, E. 2002. Post-fledging survival of individual great tits: the effect of hatching date and fledging mass. - Oikos 99: 481-488.

Morrissey, C. A. 2004. Effect of altitudinal migration within a watershed on the reproductive success of American dippers. - Can. J. Zool. 82: 800-807.

Morrissey, C. A., Bendell-Young, L. I. and Elliott, J. E. 2004. Seasonal trends in population density, distribution, and movement of American dippers within a watershed of Southwestern British Columbia, Canada. - Condor 106: $815-825$.

Mulder, R. A. 1995. Natal and breeding dispersal in a cooperative, extragroup mating bird. - J. Avian Biol. 26: $234-240$.

Murphy, M. T. 1996. Survivorship, breeding dispersal and mate fidelity in eastern kingbirds. - Condor 98: 82-92.

Newton, I. 2001. Causes and consequences of breeding dispersal in the sparrowhawk Accipiter nisus. - Ardea 89: $143-154$.

Pärt, T. and Gustafsson, L. 1989. Breeding dispersal in the collared flycatcher (Ficedula albicollis): possible causes and reproductive consequences. - Ecology 58: 305-320.

Price, F. E. and Bock, C. E. 1983. Population ecology of the dipper (Cinclus mexicanus) in the Front Range of Colorado. - Stud. Avian Biol. 7: 1-84.

Reed, J. M. and Oring, L. W. 1993. Philopatry, site fidelity, dispersal and survival of spotted sandpipers. - Auk 110: $541-551$.

Rohwer, F. C. and Anderson, M. G. 1988. Female-biased philopatry, monogamy, and the timing of pair formation in migratory waterfowl. - Curr. Ornithol. 5: 188-221.

Rowley, I. 1983. Remating in Birds. - In: Bateson, P. (ed.). Mate choice. Cambridge University Press, Cambridge, pp. 331360.

Shields, W. M. 1984. Factors affecting nest and site fidelity in Adirondack barn swallows (Hirundo rustica). - Auk 101: $780-789$.

Switzer, P. V. 1993. Site fidelity in predictable and unpredictable habitats. - Evol. Ecol. 7: 533-555.

(Received 2 August 2004, revised 13 January 2005, accepted 2 February 2005.)

Where

$\mathrm{RS}(\mathrm{m})=$ mean annual reproductive success of migrants $=$ 2.8 young per year (Morrissey 2004)

$\mathrm{S}_{\text {year } \mathrm{t}}=$ probability of surviving to year $\mathrm{t}$

given that the annual survival of breeding migrants $=$ $0.59(\mathrm{n}=34$ migrant years; Green et al. unpubl. data)

The residual reproductive value of individuals that were migrants in their first breeding season, survived to the following breeding season, and switched to being residents for the remainder of their life was calculated using Eqn 2:

$$
\begin{aligned}
\operatorname{RRV}(\text { switch })= & \operatorname{RS}_{\text {year } 2}(\mathrm{~s})-\operatorname{COST} \\
& +\sum_{\text {year } 3}^{7} \mathrm{~S}_{\text {year } \mathrm{t}} \cdot \mathrm{RS}(\mathrm{s})
\end{aligned}
$$

Where

$\mathrm{RS}(\mathrm{s})=$ mean annual reproductive success of resident dippers $=3.7$ young per year (Morrissey 2004)

$\mathrm{COST}=$ the reproductive cost of switching and is only paid in the first year 
Appendix (Continued)

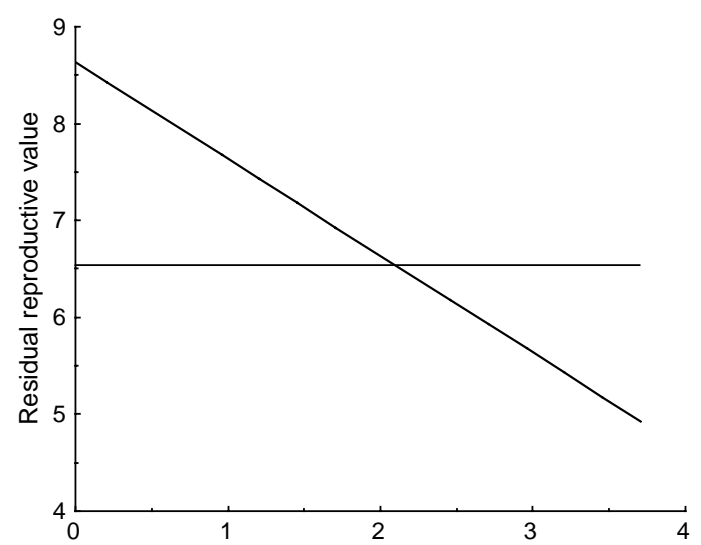

Cost of switching (reduction in number of young raised to $14 \mathrm{~d}$ )

Fig. 7. Predicted residual reproductive values for two-year old migratory birds that switch migratory strategies and become residents that breed and overwinter in the same area in relation to the cost of switching strategy. Horizontal line shows residual reproductive value of migrants that remain migratory.
$\mathrm{S}_{\text {year } \mathrm{t}}=$ probability of surviving to year $\mathrm{t}$ given that the annual survival of breeding residents $=$ $0.59(\mathrm{n}=105$ resident years, Green et al. unpublished data)

We assumed that

1) reproductive success and survival do not vary with age for adult American dippers

2) dippers breed for a maximum of seven breeding seasons (Kingery 1996)

Under these conditions the RRV of migratory dippers that do not switch strategies is 6.54 , and the RRV of migratory dippers that switch strategies varies from 8.64 if there is no cost and 4.94 if switching strategies has a reproductive cost of 3.7 young (i.e. individuals that switch on average produce no young in the year they first breed on their wintering grounds). The RRV of individuals that pursue the two strategies is equal when the reproductive cost is 2.1 young (Fig. 7). 